\title{
Integrating Mathematics and Other Learning Areas: Emerging Tensions From a Study Involving Four Classroom Teachers
}

\author{
Willy Mwakapenda \& Joseph Dhlamini \\ Tshwane University of Technology \\ mwakapendawwj@tut.ac.za \& jjthemba@yahoo.com
}

\begin{abstract}
This paper presents findings from a pilot study that investigated the extent to which teachers make connections between mathematical concepts and concepts from other disciplines. Data from concept maps and interviews were collected. The analysis revealed that the kinds of connections teachers made are closely tied to teachers' disciplines of specialisation. The findings suggest that for some teachers, though desirable, it may not be feasible to require them to make connections with disciplines that are not within their areas of specialisation. This presents tensions for learners learning mathematics in classrooms where opportunities for making connections between mathematics and other learning areas are available but are neither taken up nor appropriately used by teachers.
\end{abstract}

Many school curriculum reforms have included the notion of integration (Presmeg, 2006). In South Africa, there are calls for schooling to shift from following structured curricula marked by a separation of bodies of knowledge (Snyder, 2000), to interdisciplinary curricula.

According to Davison, Miller and Metheny (1995), the concept of integration is interpreted in many different ways. The absence of uniform commonalities in interpretations of this concept has led to the unavailability of a common definition for integration. However, with specific reference to mathematics, arguments by Adler, Pournara and Graven (2000) have identified three levels of integration: "integration of the various components of mathematics; between mathematics and everyday real world knowledge; and where appropriate, across learning areas" (p. 3). They have argued that while integration is desirable, the extent of the demands placed upon teachers makes integration less feasible. In order for teachers to integrate what they are teaching with other learning areas, teachers need not only to have a sufficient knowledge of their own learning areas, but they also need to have and be aware of a broad range of knowledges within and outside the curriculum. However, there are claims within the new curriculum that integration across learning areas should be more feasible at the lower grades than at the higher because of the difficulty of finding sufficiently generative contexts at the higher levels. According to the Department of Education (2006), contexts are "situations or conditions in which content is taught, learnt and assessed". These are derived from "different sources" such as: the nature of the learning area being taught, the socio-economic environment of learners, national and other events, interests, nature and needs of learners, and the integration of appropriate Assessment Standards from other Learning Outcomes and other learning areas (p. 27). It is generally understood that contexts are a useful way in which to "integrate" learning areas, and that ways of proceeding with integration determine what kinds of integration are possible.

The preceding remarks indicate that the introduction of the new curriculum has placed demands on teachers to adopt integrated teaching, to organise their teaching so that it promotes integration of one learning area with another. However, there have been concerns that teachers are not adequately trained to handle new curriculum demands, given that they are qualified in specific disciplines. Adler et al. (2000) have noted that 
the teacher is expected to posses a broad general knowledge of matters unrelated to his or her subject and possibly also to be an expert in other subject areas. This is clearly seldom possible and might leave the teacher feeling powerless to cope with the new demands. (p. 6)

In this paper, we focus on how teachers integrate Mathematics and the following subjects (learning areas) in the new South African school curriculum: Arts and Culture (AC), Economic and Management Science (EMS) and Science. From the given background, it is clear that there is a challenge for teachers to incorporate new pedagogical approaches that emphasise the need to integrate Mathematics and these learning areas. There is a need to understand how teachers think about integration across subjects. How they think about integration may shape how they integrate across disciplines in actual classroom practice. This paper reports on a pilot study involving four teachers: one Grade 9 AC teacher, one Grade 7 EMS teacher, one Grade 7 Mathematics teacher, and one Grade 11 Science teacher. It is important to establish how teachers deal with situations in which they are called upon to reflect on their mathematical knowledge during lesson planning and teaching. The paper reports on aspects of the following key research questions in relation to the pilot study:

- Within the context of a new curriculum in South Africa, what connections do teachers make between mathematical concepts and concepts in their disciplines of specialisation?

- What do these connections mean within the context of mathematics classroom practice in the new South African curriculum?

\section{Theoretical framework}

The study from which this paper emerged was guided by a theory of situated learning. Situated theories are founded on the premise that knowledge is situated, and is a product of the activity, context, and culture in which it is developed and used (Brown, Collins, \& Duguid, 1989). Within this perspective, one learns differently in different situations, so learning is situated within a context. Adler et al. (2000) have argued that transferring knowledge from one setting (context) to another is always problematic: "knowledge and skills cannot be neatly lifted out of one setting and imported ready-to-use into a new setting" (p. 11). The use of situated theory highlights the fact that implementing the notion of integration is potentially problematic, as Mathematics and Arts and Culture, for example, present two different learning contexts. How one links concepts from one discipline to another depends on one's understanding of the possibilities of connections that are available. Such connections are highly dependent on the contexts involved (Dhlamini, 2009; Mwakapenda, 2008).

Integration is seen to be a key driving principle of the new South African curriculum (Adler et al., 2000). After the new curriculum was introduced in South Africa, it became clear that teachers had to adopt new pedagogical approaches to teaching and learning. Teachers are expected to implement integrated teaching in their lessons. However, as already pointed out, there is a concern that teachers do not have the requisite knowledge and are not well oriented to manage the demands of integrating across disciplines (Adler et al., 2000; Czerniak, Weber, Sandmann, \& Ahern, 1999; Huntley, 1999). This raises pedagogical concerns, particularly given that teacher's content knowledge is a prerequisite in order to facilitate connections between disciplines or subjects (Huntley, 1999). Shulman (1986) presents key ideas related to the pedagogical content knowledge that teachers need in order to teach a discipline. Shulman argues that a teacher needs to be familiar with the curriculum and concepts that her students are learning in other subjects at the same time that they are studying her subject. Within the new South African context, little is known about how teachers work with the new pedagogical demands to integrate across subjects. What connections exist between Mathematics and other disciplines such as Arts and Culture, EMS, and Science?

According to Beckmann, Michelsen and Sriraman (2005), there is a "here is a "historical lineage of connections between mathematics, arts and science" (p. 2). Arts and Culture provide possibilities to visualise mathematical thinking and expressing mathematical thoughts which might be difficult to comprehend theoretically. Mathematics, on the other hand, can contribute to the solution of significant unresolved cultural and social problems, for instance, global birth control and epidemic control (Beckmann et al., 2005). On the other hand, EMS as a learning area is fairly new at the current Grade 7 
level in South Africa. It is also already an integrated learning area consisting of different subjects: economics, leadership and management, entrepreneurship and financial knowledge. In Bernstein's (1982) terms, EMS is a weakly classified subject, that is, it has the potential to allow other learning areas to integrate with it. It is widely acknowledged that mathematics and science are inextricably connected. For example, there are many school mathematics topics such as "vectors" that appear in mathematics as well as in science textbooks. Conventional science topics such as "energy" frequently incorporate mathematical concepts such as "equation". In order to develop science knowledge, scientists frequently invoke the use of mathematics. Such strong connections have even prompted mathematicians such as Gauss to refer to mathematics as "the queen of the sciences" (Bell, 1951, p. 2). Bell (1951) has provided illustrative examples of connections between mathematics and science disciplines.

As can be seen from the above, there are inherent connections between Mathematics and Arts and Culture, EMS, and Science. However, to what extent are these and other connections known to classroom teachers? What kinds of connections do teachers see between these disciplines?

\section{Study design and data collection}

A qualitative descriptive research methodology was used, and because qualitative research is inherently multi-method in focus (Naidoo \& Parker, 2005), data was collected through concept mapping tasks and interviews with teachers. Taking the perspective of Malone and Dekkers (1984), this study considered that concept maps are "windows to the minds" of the teachers we work with for reflecting on teachers' perceptions and meanings. It is viewed that maps "facilitate a sharing of meaning unhampered by any lack of verbal skills" (p. 231).

The concept mapping tasks which were administered to teachers were as follows: The Arts and Culture (AC) teacher was asked to draw a concept map involving the following concepts (selected from a topic in a Grade 9 Arts and Culture textbook): angle; area; colour; dance; design; dimension; melody; parallel; pattern; percentage; positive. The EMS teacher and the mathematics teacher were asked to draw concept maps showing links between the following concepts taken from the EMS curriculum: graph; ratio; percentage; salary; product; expand. The science teacher was asked to draw, in her own time, a concept map linking the concepts: work, equation, energy, power, solutions and function. These concept mapping tasks took place in different schools at different times. Teachers' responses to the concept mapping tasks were followed up with interviews.

\section{Research participants}

The research involved a sample of teachers, purposively selected, from participating schools in Gauteng. The AC teacher was teaching Arts and Culture on a fulltime basis and had teaching experience of approximately 15 years. The teacher indicated that he was quite familiar with both the old and the new curricula. He acknowledged having attended new curriculum training workshops. The EMS teacher had teaching experience in Economics and Business Economics at higher levels. The EMS teacher was also an EMS Masters student at a tertiary institution and had over 5 years experience teaching EMS in Grade 7. The Mathematics teacher had over 10 years' experience in teaching mathematics in Grade 7 . The Mathematics teacher was part of the transition from the old traditional curriculum to the new integrated curriculum and was an Honours student at a tertiary institution. The Science teacher was qualified as a Mathematics and Physical Science teacher, and had been teaching for nearly 20 years and was the head of department for Science and Natural Science at the time of the study.

\section{Results and observations}

\section{The Arts and Culture teacher}

Figure 1 shows the concept map drawn by the Arts and Culture teacher. As can be seen from Figure 1, there are three components in the map: it shows concepts that seem to belong to the top part "Pure Maths"; secondly, those that are "Pure Arts and Culture" concepts, and those that "Integrate between Mathematics and Arts and Culture". The teacher felt that the concepts colour, melody, dance and design were pure Arts and Culture concepts, and so could not be linked to Mathematics. This is interesting, 
particularly in light of Graumann's (2005) comments below in relation to the connection between mathematics and music:

Rhythm and notation is a relatively simple mathematical field, which provides a good opportunity for application-oriented practice of fractions. The determination of pitches and scales respectively tunes is a big chapter in which the development in the theory music from Pythagoras to twelve-tone music can be opened up by mathematics. In this context, the ancient theory of music can serve as a field of application for fractions as well. (p. 3)

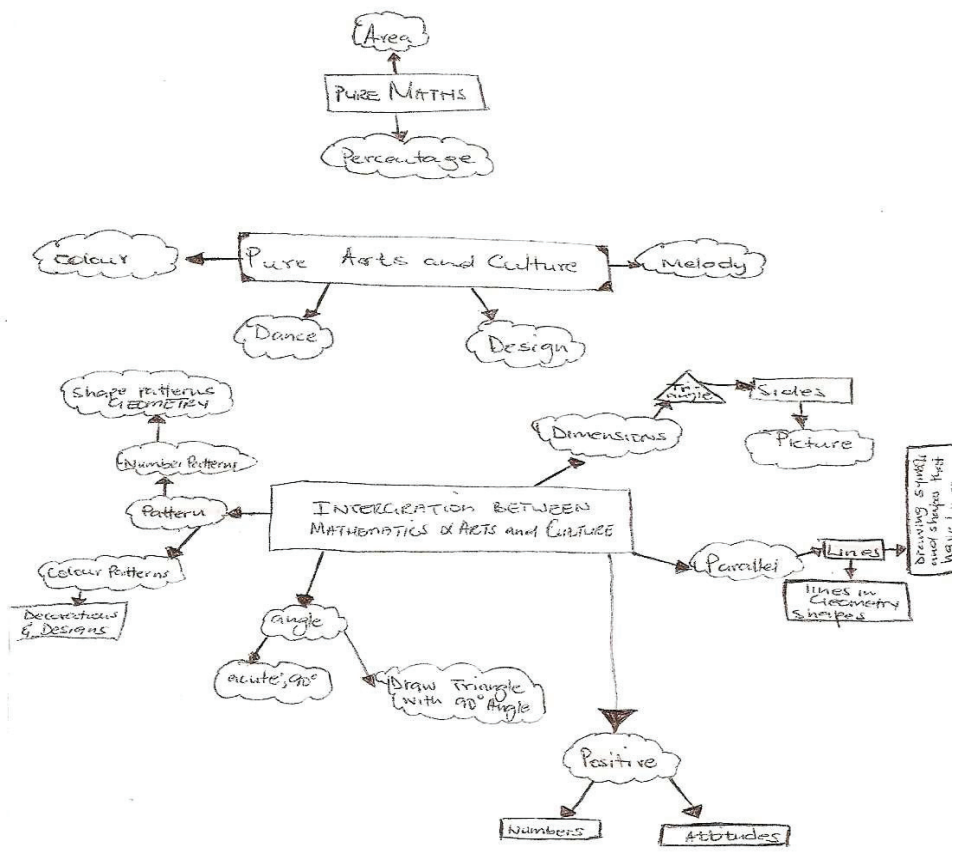

Figure 1: The Arts and Culture teacher's concept map

The absence of connections between these concepts and mathematics was further confirmed in the interview with the Arts and Culture teacher when she repeatedly stressed that the concepts colour and music could not be linked to mathematics. However she was passionate about integration and acknowledged that "teachers should be trained on integration" because some of her colleagues were "still struggling with integration". She noted that they sometimes relied on other teachers as well as learners for assistance with integration. According to her, "the learners will definitely help you, you can give them a problem, they will give you answers that you did not expect, they will integrate". She identified 'area' and 'percentage' as the only concepts that can be linked to mathematics. During the interview, she insisted that 'percentage' is a mathematics concept. She stated: "In Arts I don't talk about percentage".

The teacher noted that integration is encouraged in curriculum documents through the statement of Learning Outcomes (LO) acknowledged that some of the LOs encouraged the integration of Mathematics with Arts and Culture. She particularly quoted Assessment Standard 9 in the Grade 9 Arts and Culture Curriculum in which the concepts "positive" and "negative" are mentioned, namely that there are "positive and negative effects of television, radio, documentaries or films on our lives" (Department of Education, 2003). She acknowledged that such topics are likely to stimulate mathematical discussions, thus opening up opportunities for connections between the two subjects. She noted that learners can "learn two things at the same time" when such topics emerge during lessons.

\section{The EMS teacher and the Mathematics teacher}

Figures 2 and 3 show the concept maps drawn by the EMS teacher and the Mathematics teacher. As indicated earlier, the EMS teacher and the Mathematics teacher were given the same concept mapping task, that is, to draw a concept indicating how the concepts graph; ratio; percentage; salary; product; expand are connected. An examination of the two concept maps shows that the connections made by these two teachers are more tied to everyday situations than to mathematics. 


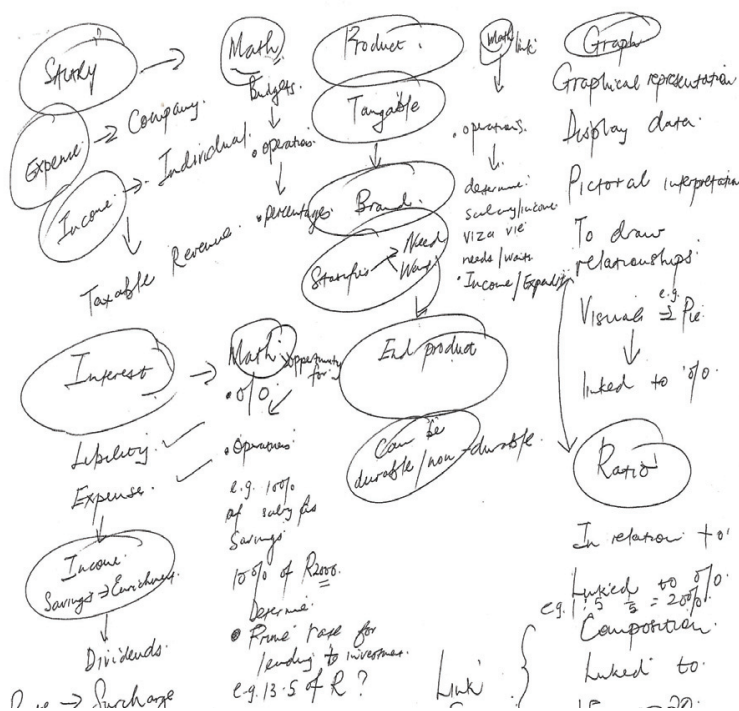

Figure 2: The EMS teacher's concept map

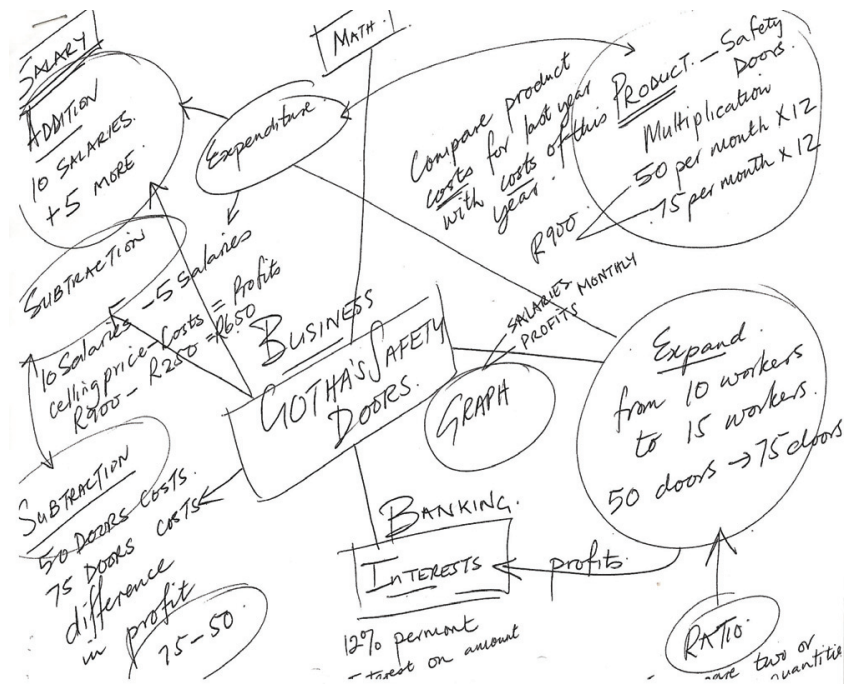

Figure 3: The Mathematics teacher's concept map

The Mathematics teacher used the everyday context of a business: "Gotha's Safety Doors". He then linked the given concepts to this context. Although this is an interesting way of making connections, it needs to be pointed out that the nature of some of the connections made may be problematic, in a mathematical sense. For example, what does the statement involving the concept expand: "Expand from 10 workers to 15 workers" (see Figure 3) mean? Increasing the workforce from "10 to 15 workers" might be considered as "expanding a business", in an everyday context. However, the concept expand has a rather different meaning in mathematics. It is interesting that the Mathematics teacher did not seem to have incorporated more mathematical connections in relation to this concept. The way the Mathematics teacher thinks about the concept product (see Figure 3) is also interesting. The links made by the EMS teacher in relation to the concept product (see Figure 2) also has connections that concern more of the everyday world than that of mathematics. Figure 2 displays an understanding of product that has an everyday and realistic association: "tangible", "end product" and products that have some "durability". While the concept maps in Figures 2 and 3 show that teachers are able to make links between concepts in EMS and Mathematics, the nature of the links appears to be highly contextualised. The understanding of the connections between concepts in this way (i.e. highly contextualised, located in a business and real world context) may be limited given that it appears to be strongly tied to one knowledge domain. An understanding that is tied to one discipline may make it difficult for teachers to integrate successfully and meaningfully as the curriculum requires.

\section{The Science teacher}

Figure 4 shows the Science teacher's concept map involving the concepts: work, equation, energy, power, solutions and function.

A look at the map shown in Figure 4 shows that it has detailed connections between concepts that are more linked to science (i.e. work, energy, power). However, the concepts solutions, function and equation are not explicitly indicated on the map. When asked to explain the absence of the concept solutions on the map, the teacher said the following during the interview:

Solutions? Is calculations isn't? I do not know what you want me to do. Can I give an example? ... You see the problems that matriculants do are quite complicated hence I did not want to put them on the map. ... You see when we give the questions, and it is long problems hence when I give a problem I don't say find a solution. I give activities where they will read and analyse, and extract information. If you want me to I can bring a textbook and we will look at an example.

As can be seen from the above interview excerpt, the teacher pointed out that she did not seem to immediately see the connections between the concept solutions and work, energy and power. However, the 
Science teacher recognised the need to use mathematics in teaching the concepts work, energy and power. The question that remains is: why didn't she include the "mathematics" concepts on her map? When asked why she did not include the concepts, she said, "I didn't know how to put them for you in a nice way". Some of her responses, such as: "Solutions? Is calculations, isn't?" indicate that the teacher was possibly uncertain on whether and how the mathematics concepts may be linked to science. This is surprising, given that the concept solution is frequently used in mathematics classrooms. This teacher had been a mathematics teacher for several years.

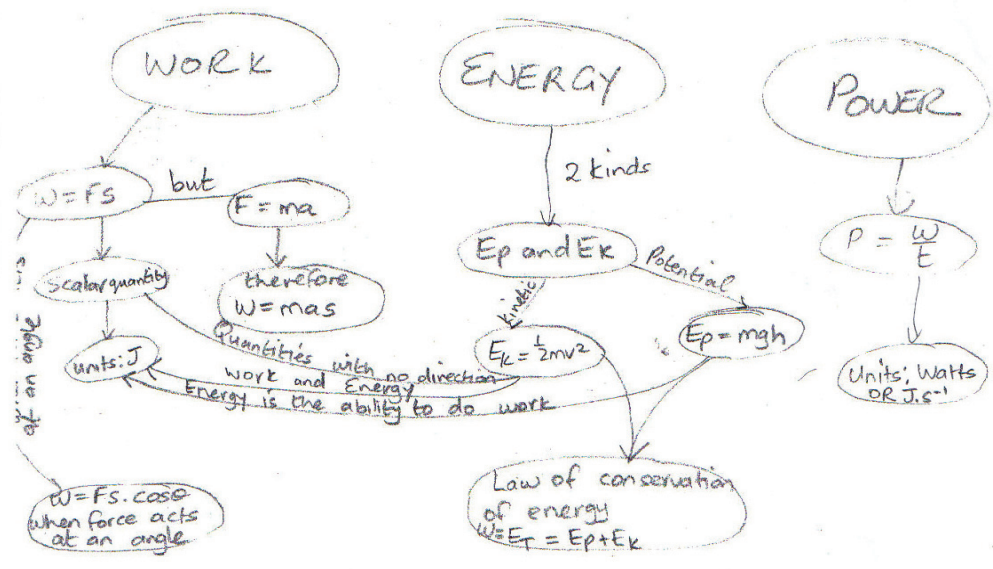

Figure 4: The Science teacher's concept map

However, the Science teacher made attempts to relate her science knowledge to mathematics. This can be seen in Figure 5, given by her during the interview.

$$
\begin{aligned}
& E_{p}=m g h \quad E_{k}=\frac{1}{2} m v^{2} \quad E_{k}=205 \\
& \begin{aligned}
m & =1009 \\
V & =?
\end{aligned} \\
& E_{k}=\frac{1}{2} m v^{2} \checkmark \quad v=\text { ? } \\
& 20=\frac{1}{2} \times 0,1 \times v^{2} \quad \frac{4}{5} \\
& v=10 \mathrm{~ms}^{-1} \alpha
\end{aligned}
$$

Figure 5: The Science teacher's use of mathematics

Clearly mathematics concepts are seen to be useful for solving problems in science. This is evident from the equation form in which the formula is written, the substitutions that have been made, and the changing of "grams" into "kilograms" and the manipulations (e.g. multiplication and division) required to obtain an answer. However, as can be seen below, the teacher pointed out that changing the subject of the formula may not be essential in science activity:

We do not mark the maths, we mark science, we want to see if learners understand that you are to use a particular equation, for example $E p=m g h$, and if you are able to substitute your $E p$, your $m$ and $g$, when you are supposed to calculate $h$. If I can see that they understand this concept I am happy. How you deal with it by making $h$ the subject is the maths teachers' problem. Say for example you are given that $E k=20 \mathrm{~J}, m=100 \mathrm{~g}$, and you are to find $v$. The first problem would be to substitute $E k$ correctly into the correct equation, the second problem would be to establish that grams are not the correct SI units. Thirdly they might try to change the subject of the formula which might be a challenge. If they do correct substitution into the correct equation, they will get 4 out of 5 marks if the final answer is incorrect... But if they try to change the subject of the formula and mess it up they get 1 out of 5 for initially using the correct formula. This is the maths teachers' problem: to ensure that the subject of the formula is changed properly, not mine. My concern is science, not mathematics. I just do not want to see them messing up my science. 
The above remarks suggest that according to the teacher, some aspects of mathematics may not be particularly important to science. Specifically, they may not be required for successful performance in science as long as those aspects "do not mess up the science". It appears that the Science teacher may allow learners to "get away" with what might be mathematical flaws provided these do not interfere with the science activity in question. This contradicts with the intentions of the South African new curriculum which encourages teacher to look inside as well as outside their learning areas.

\section{Discussion and implications}

The above analysis has demonstrated that the Arts and Culture teacher did not consider concepts such as melody and design as being linked to mathematics in spite of available evidence that these two concepts have important mathematical connections. Although the EMS teacher and the mathematics teacher were both able to link EMS concepts (e.g. product, expand) to mathematics, the nature of the links made were more related to the everyday context than to deeper mathematical meanings associated with the given concepts. While the Science teacher was able to make detailed connections between concepts that were more about science (work, energy, power), the more mathematical concepts (solutions, equation, function) were not explicitly included in her concept map. In a follow-up interview, the science teacher made it clear that making attempts to ensure that mathematical aspects of a science activity are appropriately considered may be at the expense of "messing up the science".

The findings from these four brief cases have implications for classroom practice. These cases reveal some of the complexities related to translating curriculum expectations into practice particularly in relation to the requirement that teaching needs to integrate across learning areas (Naidoo \& Parker, 2005). We need to acknowledge that working in integrated ways in the school curriculum opens up new opportunities and realities for schooling. Integration appears to be a complex activity for teachers who are likely to meet with challenges both within and beyond their specific curriculum disciplines. There is a need to understand the identities of teachers and learners (their beliefs about mathematics and learning) in order to facilitate the implementation of the notion of integration. There is a critical challenge here that concerns the mathematics, and in general, the knowledge that is needed for teaching and learning. For example, at present, we do not know much about what happens when the mathematics needed in order to enable learners to understand a science concept that requires mathematics is not well understood, both by learners and teachers themselves. The analysis in the paper demonstrates that when teaching science (or indeed any non-mathematical subject), there is a need to unpack the mathematical aspects that might be important to effect the learning that is being sought. We need to document and analyse the mathematical aspects that are inherent in a discipline or unit being taught, and to make available this knowledge to teachers. However, this analysis shows integration may not succeed in cases where the teacher is socialised to believe that their teaching roles are restricted to those subjects in which they have been trained or are "responsible" for. The analysis of the case of the Science teacher reveals some of the tensions that learners may face when studying mathematics in classrooms where opportunities for making connections between mathematics and other learning areas are available but are either neglected or inappropriately used by teachers.

\section{Acknowledgement}

This paper emerges from the research project exploring understanding of school mathematics and the use of concept mapping, supported by a grant from the National Research Foundation (NRF). We acknowledge contributions from Prevein Marnewicke and Dumazi Mkansi, who also participated in the concept mapping research. 


\section{References}

Adler, J., Pournara, C., \& Graven, M. (2000). Integration within and across mathematics. Pythagoras, 53, $2-13$.

Beckmann, A., Michelsen, C., \& Sriraman, B. (2005). Research considerations for interdisciplinary work on mathematics and its connections to the arts and sciences. In A. Beckmann, C. Michelsen, \& B. Sriraman (Eds.), Proceedings of the First International Symposium of Mathematics and its Connections to the Arts and Sciences (pp. 2-6). Hildesheim, Berlin: Verlag Franzbecker. Retrieved from http://www.franzbecker.de/langfassung/414.pdf

Bell, E. T. (1951). Mathematics: Queen and servant of science. New York: McGraw-Hill.

Bernstein, B. (1982) On the classification and framing of educational knowledge. In T. Horton \& P. Raggat (Eds.), Challenge and change in the curriculum (pp. 157-176). Milton Keynes: The Open University.

Brown, S. J., Collins, A., \& Duguid, P. (1989). Situated cognition and the culture of learning. Educational Researcher, 18(1), 32-41.

Czerniak, C., Weber, W., Sandmann, A., \& Ahern, J. (1999). A literature review of science and mathematics integration. School Science and Mathematics, 99(8), 421-430. doi: 10.1111/j.1949-8594.1999.tb17504.x

Davison, D., Miller, K., \& Metheny, D. (1995). What does integration of science and mathematics really mean? School Science and Mathematics, 95 (5), 226-230. doi: 10.1111/j.1949-8594.1995.tb15771.x

Department of Education. (2003). National curriculum statement Grades R-9 (General): Arts and Culture. Pretoria: Department of Education.

Department of Education. (2006). National curriculum statement Grades R-9 (Orientation Programme Grades 8 and 9: Part b: Mathematics facilitator's manual). Pretoria: Department of Education

Dhlamini, J. (2009). Connections between Mathematics and Arts \& Culture: An exploratory study with teachers in a South African school. In L. Paditz \& A. Rogerson (Eds.), Proceedings of the 10th International Conference of the Mathematics Education into the 21 st Century Project (pp. 139-142). Dresden, Germany: Dresden University of Applied Sciences. Retrieved from http://math.unipa.it/ grim/21_project/Dhlamini139-142.pdf

Graumann, G. (2005). Mathematical analysis of tunes within the classical theory of music. In A. Beckmann, C. Michelsen, \& B. Sriraman (Eds.), Proceedings of the First International Symposium of Mathematics and its Connections to the Arts and Sciences (pp. 176-184). Hildesheim, Berlin: Verlag Franzbecker.

Huntley, M. A. (1999). Theoretical and empirical investigations of integrated mathematics and science education in the middle grades with implications for teacher education. Journal of Teacher Education. 90(50), 57-67. doi: 10.1177/002248719905000107

Malone, J., \& Dekkers, J. (1984). The concept map as an aid to instruction in science and mathematics. School Science and Mathematics, 84(3), 220-231. doi: 10.1111/j.1949-8594.1984.tb09543.x

Mwakapenda, W. (2008). Understanding connections in the school mathematics curriculum. South African Journal of Education, 28(2), 189-202.

Naidoo, D., \& Parker, D. (2005). The implications of a mathematics teacher's identities and official mathematics discourses for democratic access to mathematics. Perspectives in Education, 23(1), 18-25.

Presmeg, N. (2006). Semiotics and the "connections" standard: Significance of semiotics for teachers of mathematics. Educational Studies in Mathematics, 61, 163-182.

Snyder, M. (2000). Broadening the interdisciplinary approach of technology education: Connections between communications, language, and the literary arts. Journal of Industrial Teacher Education, 37(4), 2-14. Retrieved on May 12, 2009, from http://scholar.lib.vt.edu/ejournals/JITE/v37n4/snyder.html

Shulman, L. (1986). Those who understand: Knowledge growth in teaching. Educational Researcher, 15(2), 4-14. 